\title{
Imipramine Administered during an Infantile Period Modifies Sex Difference in L-5-Hydroxytryptophan-Induced Head Shakes in Rats
}

\author{
Hideaki TAGUCHI and Tomoko FUJII \\ Department of Pharmacology. Teikyo University School of Medicine. \\ Kaga 2-11-1, Itabashi-ku. Tokyo 173, Japan \\ Accepted February 2, 1987
}

\begin{abstract}
Five $\mathrm{mg} / \mathrm{kg}$ imipramine or desipramine was injected to infantile rats. L-5-Hydroxytryptophan-induced head shakes were assessed when rats were mature. The saline- and desipramine-treated adult male rats exhibited more sustained response to L-5-HTP than females. The time course of the head shake frequency in the imipramine-treated male and female rats showed a pattern between control males and females, resulting in no significant sex difference. The results suggest that infantile exposure to imipramine induces an alteration of the serotonergic neurons of the brain.
\end{abstract}

The increasing number of reports have suggested that many drugs acting on the central nervous system (CNS) modify the development of the CNS in animals when these drugs are given during pregnancy or infancy (1, 2). Prenatal administration of antidepressants has been observed to induce alterations in behaviors (3), body temperature (4) or monoamine receptor characteristics (3. 5). However, effects of the postnatal exposure to antidepressants on the CNS development have not been fully investigated. We studied effects of the postnatal exposure to tricyclic antidepressants on rat brain development by examining the L-5-hydroxytryptophan ( $L-5$ HTP) -induced head shakes (6).

Five $\mathrm{mg} / \mathrm{kg}$ of imipramine (IMI) or desipramine (DMI) was injected subcutaneously to Wistar-imamichi male and female rats (Institute for Animal Reproduction. Saitama) daily from 7 to 19 days of age between 12:0015:00. Control pups received saline. All pups were weaned at 21 days of age. Animals were kept in a temperature-controlled $(22 \pm$ $3^{\circ} \mathrm{C}$ ) room with a lighting schedule of $14 \mathrm{hr}$ light (06:00-20:00) and 10 hr darkness and supplied with a stock diet (Oriental Yeast Co., Ltd.) and water ad libitum.

At 5 weeks (prepubertal) and 9 weeks (young adult) of age. these rats were tested for the L-5-HTP-induced head shakes. At
9:00 in the morning. 3 rats from each group were placed in respective clear plastic cages $(22 \times 43 \times 17.5 \mathrm{~cm})$. They were injected with carbidopa (25 $\mathrm{mg} / \mathrm{kg}$, i.p.) at $9: 30$ followed $30 \mathrm{~min}$ later by L-5HTP $(75 \mathrm{mg} / \mathrm{kg}$. s.c.), and the number of head shakes in $5 \mathrm{~min}$ was counted every $30 \mathrm{~min}$ starting $30 \mathrm{~min}$ after L-5-HTP administration.

Imipramine (Tofranil injection ${ }^{(B)}$ ) and desipramine (Pertofran Injection ${ }^{\mathbb{Q}}$ ) (Fujisawa Pharmaceutical Co., Ltd.) were diluted with distilled water to give an injection volume of $0.4 \mathrm{ml} / 100 \mathrm{~g}$ body weight. L-5-Hydroxytryptophan (Sigma Chemical Co.) was dissolved in saline containing a minimum quantity of hydrochloric acid with a final $\mathrm{pH}$ of 5.4. Carbidopa (Merck. Sharp \& Dohme) was suspended in 1\% sodium carboxymethyl cellulose (Iwai Chemical Co.). Statistical evaluation was carried out using Wilcoxon's $U$-test.

In 5-week-old rats, the head shakes appeared about $15 \mathrm{~min}$ after L-5-HTP injection, reaching a plateau in its frequency around 60-90 $\mathrm{min}$, and decreased thereafter. No significant difference in the time course of the head shake response was observed in all the saline-, IMI- and DMI-treated groups except the DMI-females which exhibited significantly less shakes than the salinefemales $60 \mathrm{~min}$ after L-5-HTP injection (Fig. 


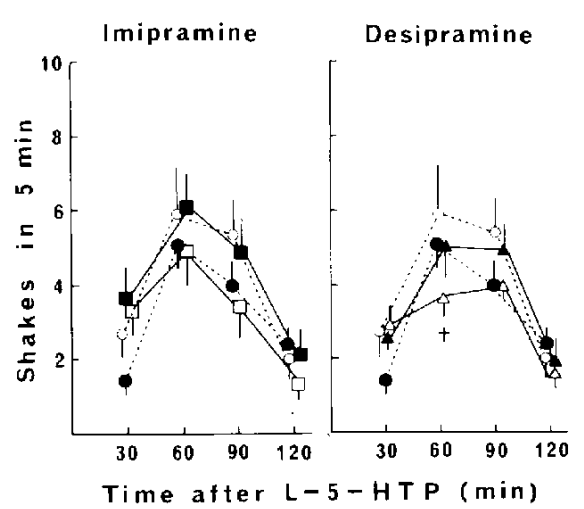

Fig. 1. Time course of the head shake response to L-5-HTP ir. 5 -week-old rats. The rats received carbidopa (25 mg/kg. i.p.) $30 \mathrm{~min}$ before L-5-HTP ( $75 \mathrm{mg} / \mathrm{kg}$, s.c.). The number of shakes was counted in a 5 -min period. Rats had been treated with saline (male --- --. female -.---), imipramine (5 mg/kg. s.c.: male - - , female - $\square-$ ) or desipramine (5 $\mathrm{mg} / \mathrm{kg}$, s.c.; male $-\mathbf{A}-$, female $-\Delta-$ ) once daily from days 7-19 of postnatal age. Each point represents the mean \pm S.E.M. of 7 rats. $\dagger, P<0.05$ vs. saline group (Wilcoxon's $U$-test)

1). At 9 weeks of age, however, the saline and DMl-treated groups showed a significant sex difference in the time course of the head shake frequency: females of both groups showed a maximal frequency of head shakes 60 min after L-5-HTP administration, whereas males of both groups responded to L-5-HTP with a sustained plateau from 60 to 120 min (Fig. 2). In contrast, the IMI-treated rats did not show the sex difference: the head shake response in the $I \mathrm{MI}$-males began to decrease $120 \mathrm{~min}$ after L-5-HTP administration instead of $150 \mathrm{~min}$, and the $\mid \mathrm{MI}$ females showed a prolonged response to $L-5$ HTP at $120 \mathrm{~min}$ as compared with the salinefemales (Fig. 2).

Two of the behavioral features, the head shake response and the serotonin behavioral syndrome $(6,7)$, have been studied extensively as behavioral models for the activation of central serotonin (5-hydroxytryptamine, 5-HT) receptors. Lucki et al. (6) have suggested that the head shake response was associated with $5-\mathrm{HT}_{2}$ receptors. whereas the serotonin behavioral syndrome was related to $5-\mathrm{HT}_{1}$ receptors. The present results may suggest the existence of a sex

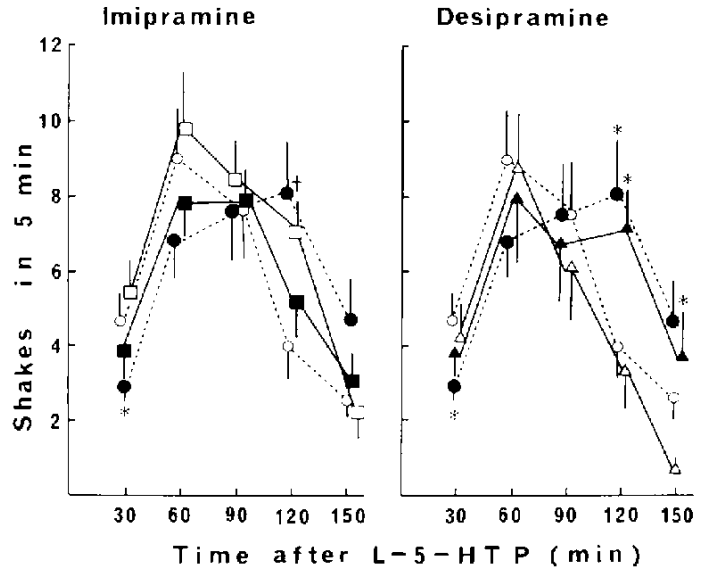

Fig. 2. Time course of the head shake response to L-5-HTP in 9-week-old rats. Rats were pretreated with carbidopa (25 $\mathrm{mg} / \mathrm{kg}$, i.p.) $30 \mathrm{~min}$ before $L-5$ HTP $(75 \mathrm{mg} / \mathrm{kg}$, s.c.). The number of shakes was counted in a 5 -min period. Symbols were the same as Fig. 1. Each point represents the mean \pm S.E.M. The number of rats examined were as follows: salinemale. 9: saline-female, 9; imipramine-maie, 10; imipramine-female, 6; desipramine-male, 6: and desipramine-female, $6 .{ }^{*}, P<0.05$ between male and female: $† . P<0.05$ vs. saline group (Wilcoxon's $U$-test).

difference in $5-\mathrm{HT}_{2}$ receptor characteristics, although biochemically no such a proof has been found.

Biegon et al. (7) described the sex difference in the serotonin behavioral syndrome in rats treated with pargyline and tryptophan. The activity of 5-hydroxytryptophan decarboxylase (5-HTPdC), the enzyme converting $5-\mathrm{HTP}$ to $5-\mathrm{HT}$, was higher in the cerebral cortex and mesodiencephalon of female rats than of males in the adult age but not 20 days of age (8). The fact that the sex difference in the time course of the head shakes was not clear until the young adult age implies that postpubertal sex hormones may play a modulatory role for this difference. The sex difference in the serotonin behaviora syndrome has been observed to be eliminated by male castration and restored by dihydrotestosterone administration. whereas ovariectomy and estrogen replacement had no effect (9). Engel et al. (10) demonstrated that testosterone exerted an inhibitory influence on 5-HT synthesis. These findings 
together with our results may support another view that androgen slows down 5-HT synthesis after puberty, leading to the sex difference of the L-5-HTP-induced head shakes at the young adult age: males showed a longer duration of the response than females.

It is well-known that $\mid \mathrm{MI}$ is metabolized to DMI in vivo. Therefore, IMI administration exhibits the effects of both IMI and DMI (11). The present result that the IMI treatment solely induced the change in the head shake time course suggests that the change was mainly due to the effect of IMI per se. It has been demonstrated that the specific high affinity $\left[{ }^{3} \mathrm{H}\right] \mid \mathrm{Ml}$ binding sites are located on 5-HT nerve terminals and associated with the 5-HT uptake mechanism and that the $\left[{ }^{3} \mathrm{H}\right] \mathrm{DM}$ l binding sites are located on noradrenaline nerve terminals and associated with the noradrenaline uptake mechanism (12). The different effects of IMI and DMI on the L-5-HTP-induced head shakes might be due to these biochemical differences. [ $\left.{ }^{3} \mathrm{H}\right]$ IMI binding sites are detectable from 5 days of postnatal age in rats (13). IMI administered from 7 to 19 days of postnatal age might have bound to these sites and possibly produced latent and subtle changes in the indoleamine metabolism, the presynaptic 5$\mathrm{HT}$ uptake system or the postsynaptic $5-\mathrm{HT}_{2}$ receptor sites, which could only be detected by assesing the response to some related drugs: changes in the time course response to L-5-HTP was an example. Although underlying mechanisms remain still unknown, the present results indicated that the exposure of infantile rats to imipramine affects the development of the central serotonergic and/or other neurons related to the manifestation of L-5-hydroxytryptophaninduced head shakes.

Acknowledgement: We are grateful to Merck. Sharp \& Dohme Research Laboratories for their generous gift of carbidopa and to Nippon Merck Banyu Co.. Ltd. for their kind arrangements.

\section{References}

1 Ikeda, H.: Pharmacological studies on the functional development of the central nervous system in first generation rats born to phenytointreated mothers. Folia Pharmacol. Japon. 79, 65-76 (1982) (Abs. in English)
2 Fuchino, K.: Effect of chronic treatment with diazepam during an infantile period on the functional development of the central nervous system in the rat. Folia Pharmacol. Japon. 80, 505-515 (1982) (Abs. in English)

3 Jason, K.M., Cooper, T.B. and Friedman, E.: Prenatal exposure to imipramine alters early behavioral development and beta adrenergic receptors in rats. J. Pharmacol. Exp. Ther. 217. 461-466 (1981)

4 Fujii, T. and Ohtaki, Y.: Sex-related hyperthermic response to chlorpromazine in the offspring of rats treated with imipramine. Dev. Pharmacol. Ther. 8, 364-373 (1985)

5 De Ceballos, M.L., Benedi, A., Urdin, C. and Del Rio, J.: Prenatal exposure of rats to antidepressant drugs down-regulates beta-adrenoceptors and $5-\mathrm{HT}_{2}$ receptors in cerebral cortex. Neuropharmacology 24, 947-952 (1985)

6 Lucki, I., Nobler, M.S. and Frazer, A.: Differential actions of serotonin antagonists on two behavioral models of serotonin receptor activation in the rat. J. Pharmacol. Exp. Ther. 228, 133-139 (1984)

7 Biegon, A., Segal, M. and Samuel, D.: Sex differences in behavioral and thermal responses to pargyline and tryptophan. Psychopharmacology (Berlin) 61, 77-80 (1979)

8 Vaccari, A., Brotman, S., Cimino, J. and Timiras, P.S.: Sex differentiation of neurotransmitter enzymes in central and peripheral nervous system. Brain Res. 132, 176-185 (1977)

9 Fischette, C.T., Biegon, A. and McEwen, B.S.: Sex steroid modulation of the serotonin behavioral syndrome. Life Sci. 35, 1197-1206 (1984)

10 Engel, J., Ahlenius, S., Almgren, $O$. and Carlsson, A.: Effects of gonadectomy and hormone replacement on brain monoamine synthesis in male rats. Pharmacol. Biochem. Behav. 10, 149-154 (1978)

11 Daniel, W., Adamus, A., Melzacka, M., Szymura, J. and Vetulani, J.: Cerebral pharmacokinetics of imipramine in rats after single and multiple dosages. Naunyn Schmiedebergs Arch. Pharmacol. 317, 209-213 (1981)

12 Langer, S.Z. and Raisman, R.: Binding of $\left[{ }^{3} \mathrm{H}\right]$ imipramine and $\left[{ }^{3} \mathrm{H}\right]$ desipramine as biochemical tools for studies in depression. Neuropharmacology 22, 407-413 (1983)

13 Mocchetti, I., Brunello, N. and Racagni, G.: Ontogenic study of $\left[{ }^{3} \mathrm{H}\right]$ imipramine binding sites and serotonin uptake system: Indication of possible interdependence. Eur. J. Pharmacol. 83, 151-152 (1982) 